\title{
Acoustic Characteristics of Composite Structures Used in Train
}

\author{
Martin Juricka ${ }^{1,2}$, Ladislav Fojtl ${ }^{1,2}$, Soňa Rusnáková3 ${ }^{3}$ Eva Juřičková 4 \\ ${ }^{1}$ Faculty of Technology, Department of Physics and Material Engineering, Tomas Bata University in Zlin, Náměstí \\ T.G.Masaryka 275, 76272 Zlin, Czech Republic, E-mail: juricka@utb.cz, fojtl@utb.cz \\ ${ }^{2}$ Centre of Polymer Systems, University Institute, Tomas Bata University in Zlin, tr. Tomase Bati 5678,76001 \\ Zlin, Czech Republic, E-mail: juricka@utb.cz, fojtl@utb.cz \\ ${ }_{3}$ Department of Production Engineering, Faculty of Technology, Tomas Bata University in Zlin, nam. T.G. Ma- \\ saryka 5555, 76001 Zlin, Czech Republic, E-mail: rusnakova@utb.cz \\ ${ }^{4}$ Department of Industrial Engineering and Information Systems, Faculty of Management and Economics, To- \\ mas Bata University in Zlin, Mostní 5139, 76001 Zlin, Czech Republic, E-mail: jurickova@utb.cz
}

This paper presents a study focused on sandwich structures as well-known train construction materials that are composed of two thin and rigid face sheets and a thick, low-density core material. For trains, the wheel-rail interface is the main source of noise, and the wheel-rail roughness, especially in the presence of rail corrugation, is the main excitation source transmitted to the interior and area for passengers. The purpose of the study is to optimize the acoustic properties of a composite sandwich panel used for train floors and walls. Sound absorption coefficient $(\alpha)$, noise reduction coefficient (NRC) and Transmission loss (TL) evaluations have been implemented and experimentally validated on a typical sandwich material used for trains. The opportunity to use a different material can be concretely calculated and modified for critical frequency ranges. Sound transmission loss levels of the structural components as the floor and wall of the train body, which are required of producers and customers, were tested in acoustic laboratory and acoustic devices according to ASTM and ISO standards. It is demonstrated that, for honeycomb and cork sandwich panels, acoustic response is not sensitive to cell size. For foam core sandwich panels, it is observed that different compositions with thin layers are effective in the frequency range of $50-1000 \mathrm{~Hz}$.

Keywords: composite structures, sound absorption coefficient, noise, train, wheel rail

\section{Introduction}

Parts and final assemblies in the transportation industry consist of a large quantity of various materials, both metallic and non-metallic, and nowadays a number of long-used materials are being replaced by newly-developed materials, particularly composites. A specific group of these advanced materials are layered sandwich structures, which stand out mainly due to their high mechanical properties (stiffness and strength) related to their weight. Traditionally, face sheets are prepared from fiber-reinforced composites or metal plates due to mechanical and impact property requirements. Traditional applications of sandwich structures in this industry sector are front end cabs, flooring, roofs, and interior and exterior panels. Each of these sandwich parts is clamped in a rigid metal frame using screw connections, rivets or adhesive bonding [1].

Zino et al. [2, 3] consider Nomex ${ }^{\circledR}$ core sandwich panels for train applications and evaluate individual components and the sandwich itself, but only with regard to the mechanical properties. This study also proposed a multiscale approach for the design and con- struction of sandwich parts in transportation. Furthermore, Belingardi et al. [4] designed, analysed and proved that structural properties of sandwich panels are dependent on the strength of foam core material. In $[5,6]$, the acoustic response of sandwich panels and also other composites is evaluated using different surroundings.

There are many sources of noise and vibration in the railway system. The dominant source at most speeds is rolling noise, which increases with train speed $\mathrm{V}$ at a rate of about $30 \log 10 \mathrm{~V}$, i.e., a $9 \mathrm{~dB}$ increase in the sound level for a doubling of speed. Traction noise is much less dependent on train speed, so that it is often dominant only at low speeds. Conversely, aerodynamic noise has a much greater speed dependence than other sources and so becomes dominant at high speeds $[4,10]$.

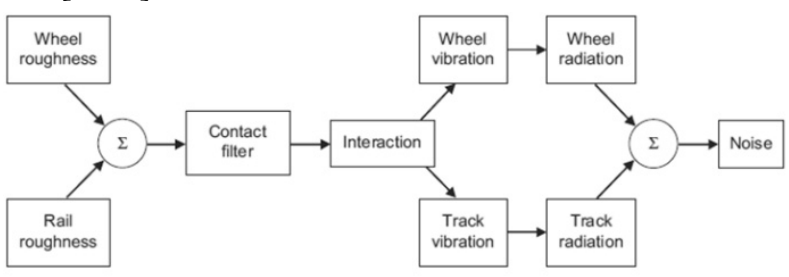

Fig. 1 Model for rolling noise generation [1, 10] 


\section{Noise}

Rolling noise - the most important source of noise from railways is rolling noise, caused by wheel and rail vibrations induced by wheel/rail contact. Roughness on the wheel and rail running surfaces induce vertical vibrations of the wheel and rail systems according to their dynamic properties. Figure 1 indicates this in the form of a flowchart, while Fig. 2 shows the mechanism visually. The main wavelengths of roughness that are relevant to rolling noise are between about 5 and $500 \mathrm{~mm}$. Typically, wheels fitted with cast-iron brake blocks have a large roughness with wavelengths around $40-80 \mathrm{~mm}$. For a train travelling at a speed of $100 \mathrm{~km} / \mathrm{h}$, this roughness excites frequencies where the track vibration radiates the most sound.

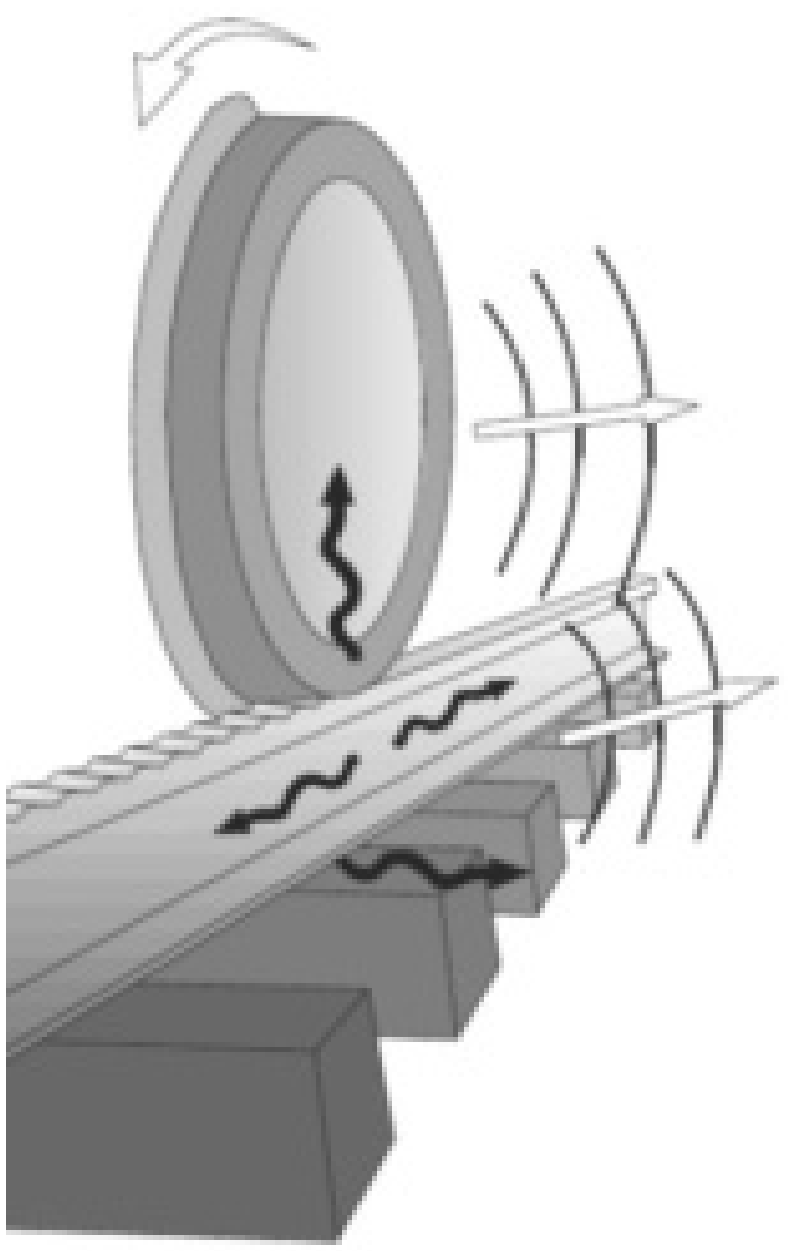

Fig. 2 Mechanism of generation of rolling noise [11]

The wheel/rail region is often the major source of noise. Additionally, on vehicles with underfloor diesel engines, noise from the engine, exhaust, intake, cooling fans and transmission system can all be significant. Noise from the air-conditioning system can also require consideration in modern rolling stock, as there is often limited space in which to package the air-conditioning unit and ducts. Also some care has to be taken in fixing equipment, such as compressors under the floor structure of a carriage or on the roof. Noise is transmitted from each of these sources to the interior by both airborne and structure-borne paths, as shown in Fig. 3.

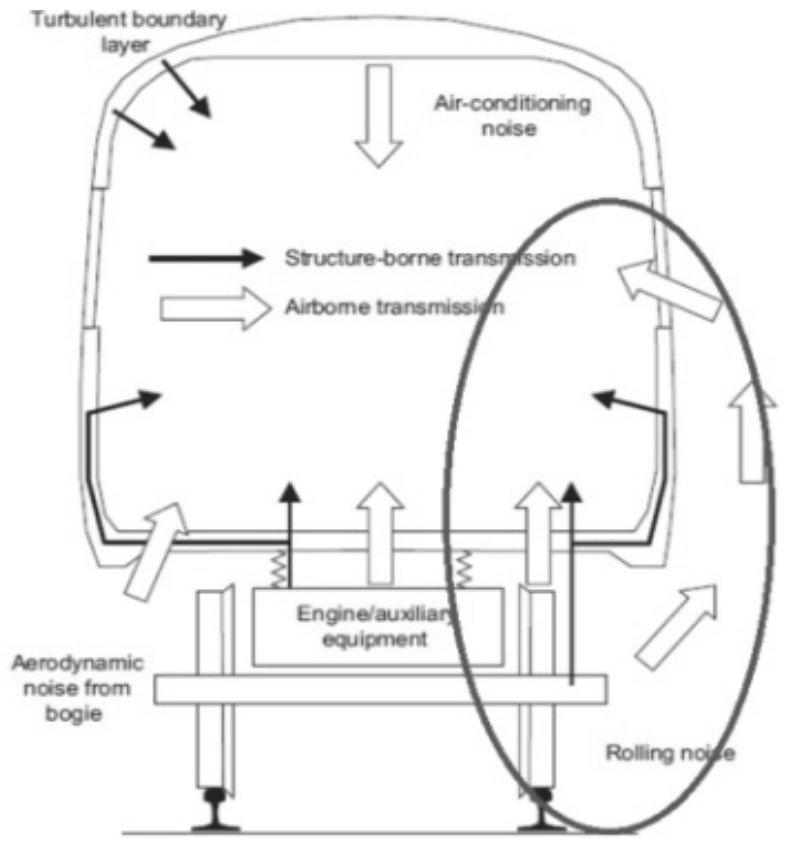

Fig. 3 The main sources of interior noise in a train and their transmission paths into the vehicle

The sound power, $\mathrm{W}$, radiated by a vibrating object in a particular frequency band can be written as follows

$$
W=\rho_{0} \cdot c_{0} \cdot S \cdot v^{2} \cdot \sigma[\mathrm{W}]
$$

Where:

@o... density of air

$c_{0} \ldots$ is the speed of sound, which take the values $1.2 \mathrm{~kg} / \mathrm{m}^{3}$ and $343 \mathrm{~ms}^{-1}$ respectively at $20 \mathrm{C}^{\circ}$

$S \ldots$ is the surface area of the vibrating structure

$v^{2} \ldots$ is the squared velocity normal to the surface in the frequency band of interesth is averaged both over time

$\sigma \ldots$ is radiation ratio of radiation efficiency .

Sandwich panels - as membrane-type sound absorbers, are usually composed of an interior wall and its back space, except in cases where they are designed and installed for a specific purpose. Thus, the interior surfaces must be reinforced and supported by a structural element such as a frame and a joist. Honeycombs can also serve as reinforcement. However, when the panel is intended to absorb sound, the vibration of the panel can be disturbed, and sound absorption may deteriorate if the panel is tightly bonded to the honeycomb[7].

The efficiency of the sandwich construction is derived from the proper choice of both face and core materials and from the adhesion between them. A sandwich panel can improve some acoustical and structural requirements, decreasing mass [8]. 


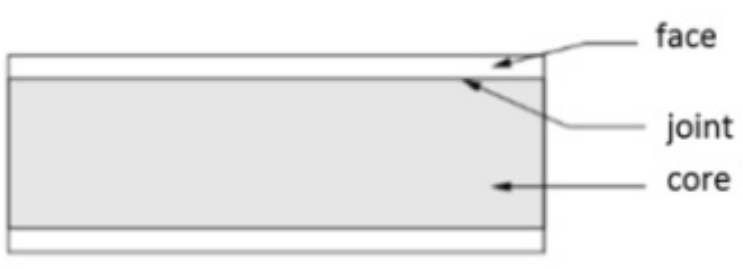

Fig. 4 The configuration of a typical sandwich structure

Sandwich panels are complex, three-dimensional, thin-walled structures for which the numerical method is the most commonly employed method to analyse the dynamic behaviour of thin-walled sandwich panels with different types of core geometries [9]. Properties of cork cores are given mainly by the size of cork wood grains, tree country of origin and quality of cork panel production.

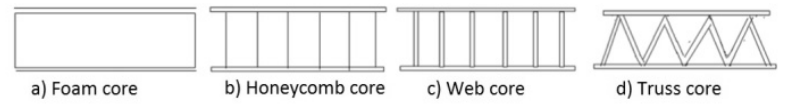

Fig. 5 Types of sandwich constructions with different kinds of cores (structural profile)

Panel and membrane type sound absorbers have long been used for sound absorption, especially at low frequencies. They have also been employed recently for various purposes as substitute materials for porous sound absorbers with environmental issues. Therefore, a new type of panel/membrane absorbers has been proposed as a next generation sound absorber.

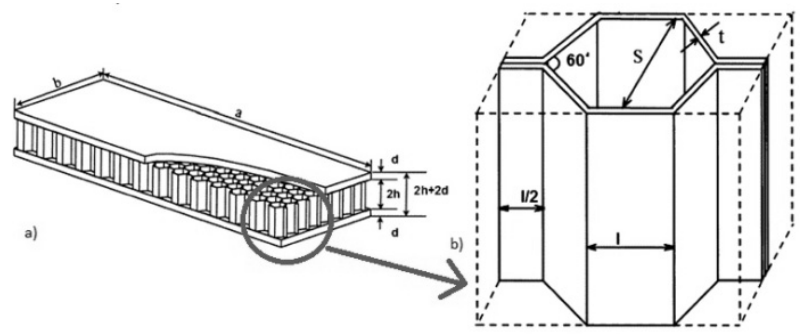

Fig. 6 a) Dimensions of a honeycomb core sandwich panel, b) dimensions of a unit cell honeycomb core.

Sound power level (SPL) can be calculated using the equation as follows:

$$
S P L=10 \log \left(\frac{w}{w_{\text {ref }}}\right)[\mathrm{dB}]
$$

Where:

$W_{r e f \ldots} 0^{-12} \mathrm{~W}$.

The value of the sound absorption coefficient $(\alpha=$ 0 ) represents the perfect sound reflection from the material surface. Where all incident acoustic energy is absorbed, the value of the sound absorption coefficient is $a=1$. The value of the sound absorption coefficient depends on many factors, e.g., on material type, sandwich material combinations (including the influence of material sequence in view of the incident acoustic energy $P_{i}$ ), frequency of the acoustic wave, material thickness and structure, surface form, size of air space, temperature and humidity. Suitable materials in terms of sound absorption achieve in a substantial part of the entire frequency range the value of the sound absorption coefficient $a>0.6$. Materials with porous, fibrous and spongy structures belong in general among suitable materials for noise damping $[8,16$, 17].

In the samples, the following are analysed:

- Sound Absorption Coefficient (a)

- Sound Reflection Coefficient ( $\beta)$

$$
\begin{aligned}
\boldsymbol{\alpha} & =\left(\frac{\boldsymbol{P}_{\boldsymbol{d}}}{\boldsymbol{P}_{\boldsymbol{i}}}\right) \\
\boldsymbol{\beta} & =\left(\frac{\boldsymbol{P}_{r}}{\boldsymbol{P}_{\boldsymbol{i}}}\right) \\
\boldsymbol{\tau} & =\left(\frac{\boldsymbol{P}_{\boldsymbol{d}}}{\boldsymbol{P}_{\boldsymbol{i}}}\right)
\end{aligned}
$$

Where:

$P_{d} \ldots$ refers to the sound power damped

$P_{r} \ldots$ sound power reflected

$P_{t} \ldots$ sound power of transmitted

$P_{i} \ldots$ impact sound power

As mentioned, the size of the sound absorption coefficient depends mainly on the excitation frequency of the incident acoustic wave. For this reason, the noise reduction coefficient (NRC) was defined as a comparative quantity in terms of a material's ability to absorb noise.

$$
N R C=\left(\frac{f_{250+} f_{500}+f_{1000}+f_{2000}}{4}\right)[-]
$$

Where a is:

$f_{250} \ldots$ value sound absorption coefficient in frequency $=250 \mathrm{~Hz}\left(f_{500}=500 \mathrm{~Hz}, f_{1000}=1000 \mathrm{~Hz}\right.$ and $f_{2000}=2000 \mathrm{~Hz}$ etc. [10].

\section{Experiments}

The selected material for the face sheets of all prepared sandwich structures was an E-glass, fiber-reinforced, phenolic resin, pre-impregnated material ("prepreg") with a thickness after curing equal to $0.234 \mathrm{~mm}$. This prepreg material has a real weight of $525 \mathrm{~g} / \mathrm{m}^{2}$ and is suitable for rail application due to its excellent FST properties. In total, three core material types were used in the prepared structures:

- An $82 \mathrm{~kg} / \mathrm{m}^{3}$ hexagonal aluminium honeycomb with a cell size of $6.4 \mathrm{~mm}$ and a 65 $\mathrm{kg} / \mathrm{m}^{3}$ hexagonal polypropylene honeycomb with a cell size of $8 \mathrm{~mm}$

- Cork materials with densities of $120 \mathrm{~kg} / \mathrm{m}^{3}$

All used materials are standardly applied for parts and constructions used in the transport industry and also many other sectors. Individual manufactured sandwich structures are described in Tab. 1 . 
Tab. 1Material composition of prepared sandwich structures $(P-$ prepreg, $C-$ core)

\begin{tabular}{|c|c|c|c|}
\hline Structure & Core material (symbols) & $\begin{array}{l}\text { Core thic- } \\
\text { kness (mm) }\end{array}$ & Sample composition \\
\hline & AL honeycomb (AL_9) & 9 & $2 x \mathrm{P} / 1 \mathrm{x} C / 2 \mathrm{x} P$ \\
\hline & PP honeycomb (PP_10) & 10 & 2x P / 1x C / 2x P \\
\hline & PP honeycomb (PP_5-5) & $5-5$ & 2x $P / 1 x C / 1 x P / 1 x C / 2 x P$ \\
\hline & Cork 120 kg/m³ (C1_9) & 9 & 2x $P / 1 x C / 2 x P$ \\
\hline & Cork $120 \mathrm{~kg} / \mathrm{m}^{3}$ (C1_6-3) & $6-3$ & 2x $P / 1 x C / 1 x P / 1 x C / 2 x P$ \\
\hline & $\begin{array}{l}\text { Cork } 120 \mathrm{~kg} / \mathrm{m}^{3} \\
\quad\left(\mathrm{C} 1 \_3-3-3\right)\end{array}$ & $3-3-3$ & $2 \mathrm{x} P / 1 \mathrm{x} C / 1 \mathrm{x} P / 1 \mathrm{x} C / 1 \mathrm{x} P / 1 \mathrm{x} C / 2 \mathrm{x}$ \\
\hline
\end{tabular}

All acoustic tests were performed in a Kunds tube, where two types of samples can be used differing in diameter:

- Samples for the frequency range $20-1600 \mathrm{~Hz}$ are with a diameter of $100 \mathrm{~mm}$,

- Samples for the frequency range 800 $6400 \mathrm{~Hz}$ are with a diameter of $30 \mathrm{~mm}$,

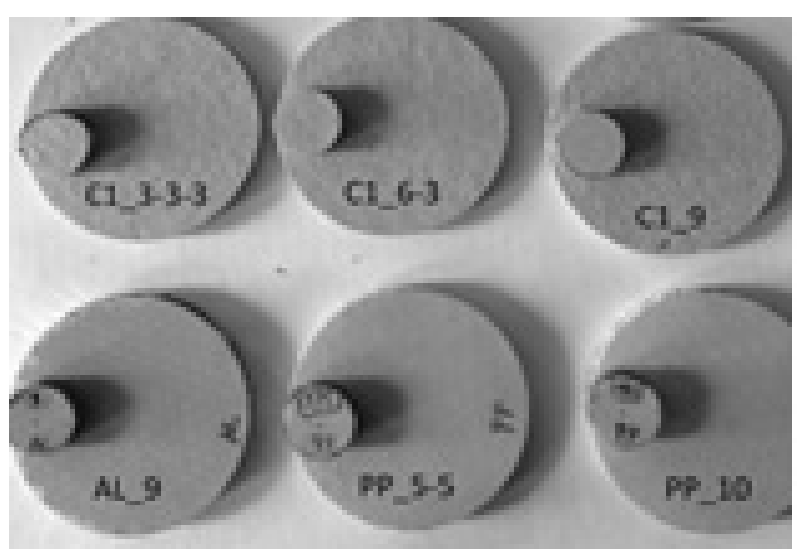

Fig. 7 Samples for testing for all series (diameter 30 and $100 \mathrm{~mm}$ )

Devices and process - there are two standards [1, 2] for the measurement of acoustical properties of materials: ASTM E1050 and ISO 10534-2. These standards establish acceptable conditions under which reliable data may be obtained; however, good practice suggests that equipment and test conditions exceed the minimal requirements of the standards $[1,2,3,4]$

The standard and modified two-microphone tube is shown schematically in Figure 8. A sample of the material to be tested is placed in a samples holder and mounted to one end of a straight tube. A sound source, typically a high-output acoustic driver, is connected at the opposite end of the tube. A pair or microphones are mounted flush with the inner wall of the tube near the sample end of the tube.

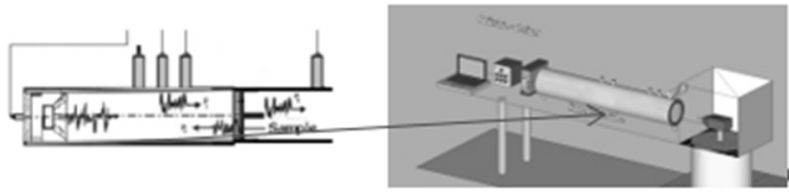

Fig. $\boldsymbol{8}$ Modified devices for measurement of sound absorption coefficient and transmission loss (acoustic properties of composite samples, BaK devices with un-bureaucratic box)

For the analyses of typical noise source by train was used acoustic camera Bionic XS handheld microphone array consists with 40 microphones (Fig 9). Together with the acoustic camera was used the software "Noise Inspector" for visualizing noise sources (contact rails and wheels).

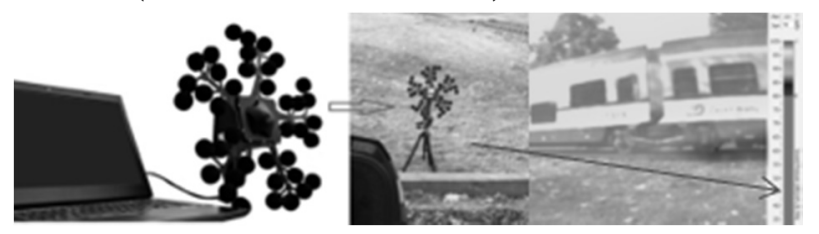

Fig. 9 Acoustic camera arranged in terrain measurement (and city railway)

Prepreg materials consist of a defined amount of resin in their volume, and thus no additional adhesive layer is necessary to bond the face sheets to the core (Fig. 10). Every face is created by two prepreg layers having a stacking sequence of [0/90]. One reinforcing layer in some sandwich structures has a $0^{\circ}$ orientation 
(see Tab. 1). The materials were bonded together in a curing oven at a ramping temperature up to $130^{\circ} \mathrm{C}$ at $2{ }^{\circ} \mathrm{C} / \mathrm{min}$ and maintaining this temperature value under a constant vacuum pressure of $0.08 \mathrm{MPa}$ for 120 minutes.

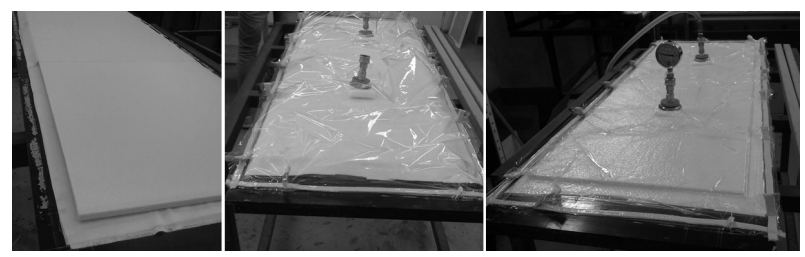

Fig. 10 Manufacturing process of sandwich structure using prepreg curing in the oven

\section{Results}

For the sound detection of a main noise source in the field, measurements with a CAE acoustic camera were taken at a regional railway track. The test was conducted under these conditions:

- Offline analyse of contact between train and rail $\left(\right.$ detection in speed $\left.=35-40 \mathrm{~km} \cdot \mathrm{h}^{-1}\right)$

- Frequency analysis with the software Noiseinspector (time in seconds)

- FFT analyse of frequency range 20 - 10000 $\mathrm{Hz}$

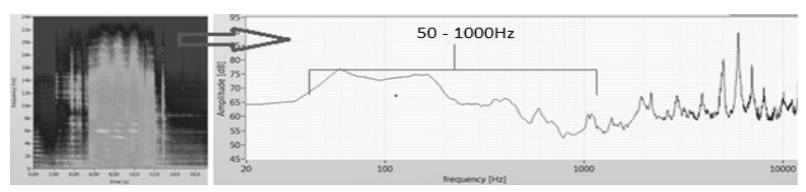

Fig. 11 Diagram of noise frequency range (left) and amplitude of FFT analyse (right)

Sound absorption coefficient and NRC sample symbols used for the measurement of sound absorption and transmission loss are shown in Table 2. For the analysis of acoustic absorption, two variants with/without an air gap - were chosen. The air cavity is the space between the end piston and the tested sample inside the tube. The sizes of this air gap were set to 10,20 and $30 \mathrm{~mm}$.
Tab. 2 Description of symbol (samples)

\begin{tabular}{|c|l|}
\hline Symbol & Description of samples \\
\hline AL & Type of sample \\
\hline PP & Type of sample \\
\hline $5-5$ & $\begin{array}{l}\text { Thickness of sample }=5 \mathrm{~mm}+5 \mathrm{~mm} \\
\text { (dev }=0,1 \mathrm{~mm})\end{array}$ \\
\hline 10 & $\begin{array}{l}\text { Thickness of sample }=(10,0 \pm 0,1) \\
\text { mm }\end{array}$ \\
\hline $10 ; \_20 ;$ & $\begin{array}{l}\text { Source }- \text { sample }- \text { air cavity } 10,20, \\
\text { and } 30 \mathrm{~mm}\end{array}$ \\
\hline
\end{tabular}

Sound absorption coefficient: The curves of the honeycomb core samples AL and PP are shows in Fig. 14. These curves show sound absorption coefficients in a frequency range between 50-5000 $\mathrm{Hz}$. Sample PP_10_30 exhibits, in combination with the greatest air gap, sufficient sound absorption that is applicable in technical practice. The material combination PP_55 is not practically applicable for sound absorption but can be used for noise shielding.

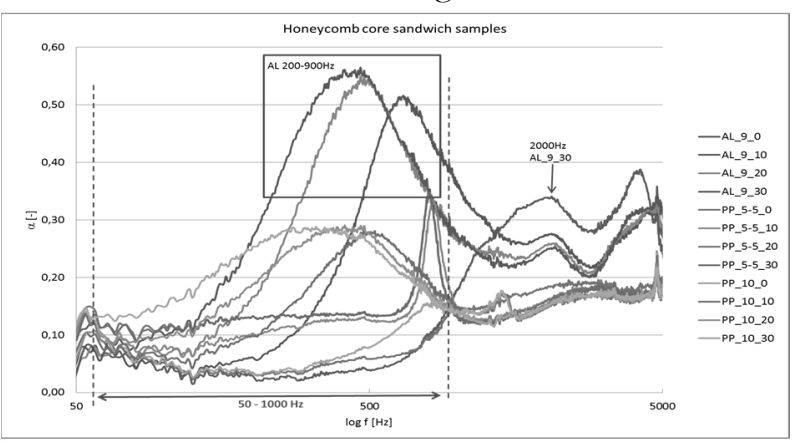

Fig. 12 Sound absorption coefficients for samples $A L$ and $P P$

NRC: coefficients of the AL and PP samples (Tab. 3) do not exceed a value of 0.4 , where the highest value of 0.36 was found for sample AL_9_30. These values are, in practice, similar to those of plywood or carpet. Due to the honeycomb core in this type of material structure, the absorption coefficient is relatively high. This also results in a high number of the NRC, as shown in Table 3.

Tab. 3 Results of the NRC (Noise reduction coefficient) for samples AL and PP

\begin{tabular}{|c|c|c|c|c|}
\hline Samples & AL_9_0 & AL_9_10 & AL_9_20 & AL_9_30 \\
\hline NRC & 0.15 & 0.28 & 0.33 & 0.36 \\
\hline Samples & PP_5-5_0 & PP_5-5_10 & PP_5-5_20 & PP_5-5_30 \\
\hline NRC & 0.11 & 0.14 & 0.14 & 0.14 \\
\hline Samples & PP_10_0 & PP_10_10 & PP_10_20 & PP_10_30 \\
\hline NRC & 0.10 & 0.18 & 0.20 & 0.21 \\
\hline
\end{tabular}

Fig. 13 depicts C1 samples with a cork core structure. The acoustic absorption of these samples is generally quite low. Absorption values in the examined frequency range from 50 to $1000 \mathrm{~Hz}$ are around a value of 0.05 . This characteristic is similar to smooth and hard surfaces, which are not suitable for sound absorption. On the other hand, these properties of $\mathrm{C} 1$ samples can provide a high degree of reflectance and transmission loss. The properties of the $\mathrm{C} 1$ material structure samples are described by the NRC, and specific values are given in Table 4. 
Tab. 4 NRC for sample C1

\begin{tabular}{|c|c|c|c|c|}
\hline Samples & C1_3-3-3_0 & C1_3-3-3_10 & C1_3-3-3_20 & C1_3-3-3_30 \\
\hline NRC & 0.07 & 0.07 & 0.06 & 0.06 \\
\hline Samples & C1_6-3_0 & C1_6-3_10 & C1_6-3_20 & C1_6-3_30 \\
\hline NRC & 0.08 & 0.08 & 0.07 & 0.07 \\
\hline Samples & C1_9_0 & C1_9_10 & C1_9_20 & C1_9_30 \\
\hline NRC & 0.07 & 0.07 & 0.07 & 0.06 \\
\hline
\end{tabular}

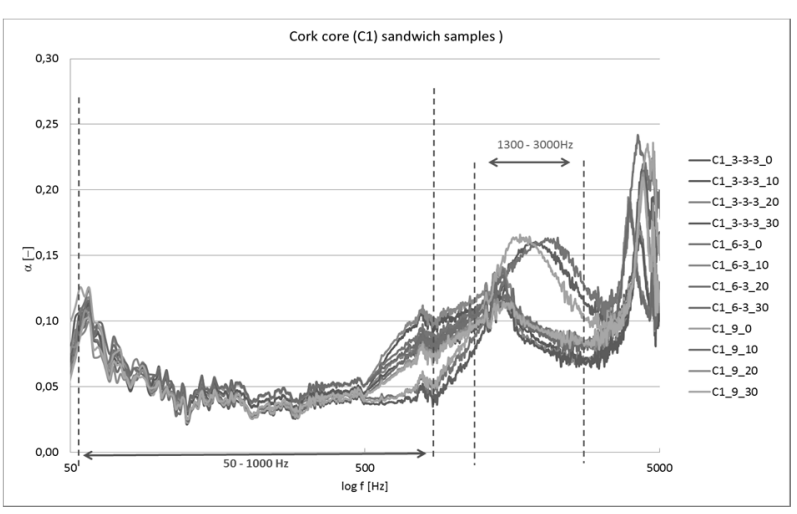

Fig. 13 Sound absorption coefficient for sample C1

Transmission loss - Impedance tube was changed as alternative tube with source for testing of transmission loss (see Fig. 14). shows SPL curves for samples with honeycomb cores (PP and AL) which show maximal attenuation in the frequency range of $50-1000 \mathrm{~Hz}$. The highest attenuation was achieved at a frequency of $63 \mathrm{~Hz}$. Curves for the sample PP10 show stable attenuation between $63-1000 \mathrm{~Hz}$. regardless the sample side to which the audio signal was turned. Other combinations of PP and AL honeycomb core sandwich samples showed similar SPL attenuation which with increasing frequency decreased to a value of $1000 \mathrm{~Hz}$ (red ellipse). The AL core samples showed around $1000 \mathrm{~Hz}$. the lowest values of attenuation. This decline is probably caused by much smaller cell wall thicknesses compared to PP honeycomb cells.

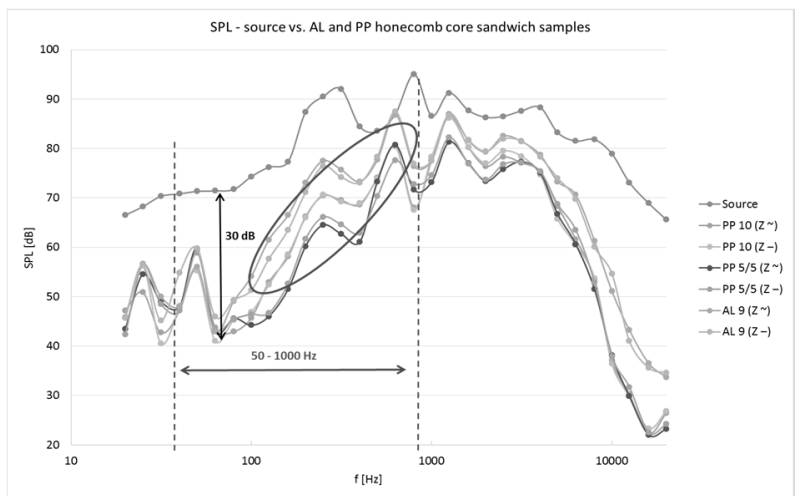

Fig. 14 Sound pressure level for samples $A L$ and $P P$

In contrast to Fig. 14. the attenuation values for selected cork samples gradually declined. This is obvious for curves that are depicted in following graph (Fig. 15). It was found that the sound attenuation cha- racteristics of all C1 samples are similar in all the combinations of cork layers in the prepared sandwich composites. This trend is particularly apparent in the area between $50-1000 \mathrm{~Hz}$. Attenuation at the beginning of the monitored frequency spectrum $(50 \mathrm{~Hz})$ is around $38 \mathrm{~dB}$, while at the upper limit of the frequency band $(1000 \mathrm{~Hz})$ a gradual decrease of attenuation occurs up to a value of $20 \mathrm{~dB}$.

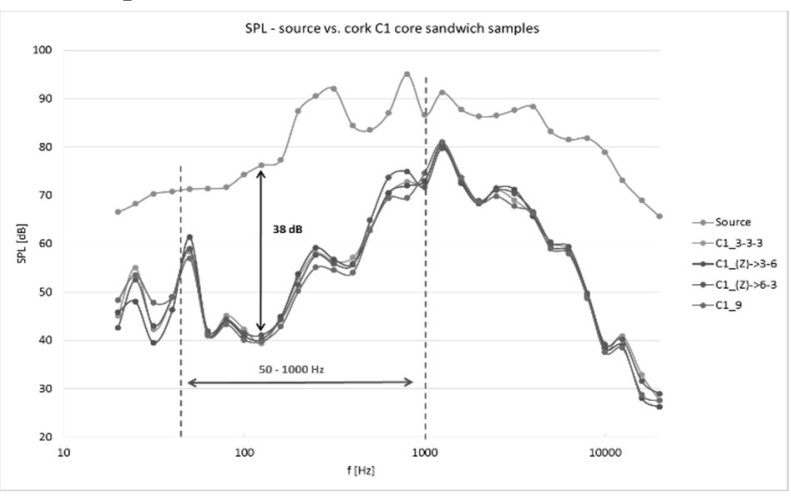

Fig. 15 Sound pressure level for C1 samples

\section{Conclusion}

For this study, special commercial materials were selected based on cork, composite, pores and aluminium for the walls, floor and roof of a train. The typical characteristics of materials used in trains are hardness and strength. For all applications, train materials are light, low density structures. The acoustic responses and sound transmission characteristics of aluminium honeycomb, composite honeycomb, core multisandwich panels and porous composite sandwich panels are compared on a selected major frequency range between $50-1000 \mathrm{~Hz}$. This frequency range was determined to be the main sound field generated on a railway. The overall preview is focused on the sound absorption and transmission characteristics of selected materials.

All the samples show high levels of transmission properties but very low capabilities for absorption of acoustic energy. Results of transmission loss properties, such as damping over a barrier, were up to $40 \mathrm{~dB}$ in selected frequencies. On the other hand, the sound absorption coefficient is very low. Maximums of absorptions start between $3500-5000 \mathrm{~Hz}$. These frequencies are in acoustic emission by the trains in minimums. In this case, the NRC coefficient is also in lower values. In selected frequencies, low values of the 
alfa coefficient were obtained that are, used for calculating the NRC.

The analysed material structure shows interesting properties that can be used for train applications. Installation of this material structure can be made in the walls, panels or undercarriage of a train.

\section{Acknowledgement}

This article was written with support of the Operational Program Research and Development for Innovations, co-funded by the European Regional Development Fund (ERDF) and the national budget of the Czech Republic, within the framework of the project Centre of Polymer Systems (reg. number: CZ.1.05/2.1.00/03.0111).

This work was supported by the Ministry of Education, Youth and Sports of the Czech RepublicProgram NPU I (LO1504). This study was also supported by TBU grant numbers IGA/FT/2016/013, IGA/FT/2017/002 and $I G A / F T / 2017 / 011$, funded from the resources of specific university research.

This work was financially supported by the Ministry of Education, Youth and Sports of the Czech Republic within the NPU I program (Grant no. LO1504) and by the European Regional Development Fund (Grant No. CZ.1.05/2.1.00/19.0409).

\section{References}

[1] ZENKERT, D. (1997). Nordic Industrial Fund. The Handbook of Sandwich Construction, first ed., EMAS Publishing, Worcestershire, 1997.

[2] ZINNO, A., FRUSCO, E., PROTA, A., MANFREDI, G. (2011). Multiscale approach for the design of composite sandwich structures for train application, Comp. Structures 92, 2208-2219.

[3] ZINNO, A. PROTA, A., DI MAIO, E., BAKIS, C.E. (2011). Experimental characterization of phenolic-impregnated honeycomb sandwich structures for transportation vehicles, Comp. Structures 93, 2910-2924.

[4] BELINGARDI, G., CAVATORTA, M.P., DUELLA, R. (2003) Material characterization of a composite-foam sandwich for the front structure of a high speed train, Comp. Structures 61, 13-25.

[5] LI, X., YU, K. (2015). Vibration and acoustic responses of composite and sandwich panels under thermal environment, Comp. Structures 131, 1040-1049.

[6] ZHAO, X., GENG, Q., LI, Y. (2013). Vibration and acoustic response of an orthotropic composite laminated plate in a hygroscopic environment, J. Acoust. Soc. Am. 133, 1433-1442.

[7] TOYODA, M., SAKAGAMI, K., TAKAHASHI, D., MORIMOTO, M. (2011). Effect of a honeycomb on the sound absorption characteristics of panel-type absorbers, $A p$ plied Acoustics 72, 943-948.

[8] COCCHI, L., ANDREINI, P., CASSITTO, L., SIANO, D., VISCARDI, M., PANZA, M. A. (2015). Acoustic Optimization of a High-speed Train Composite Sandwich Panel Based on Analytical and Experimental Transmission Loss Evaluation Integrated by FE/Test Correlation Analysis, Energy Procedia 81, 689-703.

[9] ARUNKUMAR, M.P., PITCHAIMANI, J., GANGADHARAN, K.V., LENIN BABU, M.C. (2016). Influence of nature of core on vibro acoustic behavior of sandwich aerospace structures, Aerospace Science and Technology 56 (2016) 155-167.

[10] CROCKER, M. J. (2007), Handbook of Noise and Vibration Control, first ed., John Wiley \& Sons, Canada.

[11] Thompson, D. (2009). Railway Noise and Vibration, Mechanisms, Modelling and Means of Control, first ed., Elsevier Science, Oxford.

[12] ASTM E1050-12 (2012). Standard Test Method for Impedance and Absorption of Acoustical Materials Using a Tube, Two Microphones and a Digital Frequency Analysis System, ASTM International, West Conshohocken, PA.

[13] ISO 10534-2 (1998). Acoustics - Determination of sound absorption coefficient and impedance in impedance tubes - Part 2: Transferfunction method, International Organization for Standardization.

[14] SEYBERT, A. F., ROSS, D. F. (1977). Experimental Determination of Acoustic Properties Using a Two-Microphone Random-Excitation Technique, J. Acoust. Soc. Am. 61, 1362-1370.

[15] CHUNG, J. Y., BLASER, D. A. (1980). Transfer Function Method of Measuring In-Duct Acoustic Properties I. Theory and II. Experiment, J. Acoust. Soc. Am. 68, 907-921.

[16] SVOBODA, M., SCHMIDT, V., SAPIETA, M., JELEN, K., LOPOT, F. (2019). Influence of the Damping System on the Vehicle Vibrations, In: Manufacture Technology, vol. 19, No. 6 (2019) pp 1034-1040, ISSN: 1213-2489.

[17] KLIMENDA, F., SOUKUP, J., ŠTĚRBA, J., Noise and Vibration Analysisi of Conveyor Belt, In Manufacture Technology, vol. 19, No. 4 (2019) pp. 604 - 608, ISSN: 1213-2489 